\title{
Article \\ Pharmaceutical and Antibiotic Pollutant Levels in Wastewater and the Waters of the Zarqa River, Jordan
}

\author{
Makoto Shigei $^{1}{ }^{\circledR}$, Almoayied Assayed ${ }^{2}$, Ayat Hazaymeh ${ }^{2}$ and Sahar S. Dalahmeh ${ }^{1, *}$ \\ 1 Department of Earth Sciences, Uppsala University, P.O. Box Villavägen 16, SE 75338 Uppsala, Sweden; \\ makoto.shigei@geo.uu.se \\ 2 Royal Scientific Society, P.O. Box 1438, Amman 11941, Jordan; Almoayied.Assayed@rss.jo (A.A.); \\ Ayat.Hazaymeh@rss.jo (A.H.) \\ * Correspondence: Sahar.Dalahmeh@geo.uu.se
}

Citation: Shigei, M.; Assayed, A.; Hazaymeh, A.; Dalahmeh, S.S. Pharmaceutical and Antibiotic Pollutant Levels in Wastewater and the Waters of the Zarqa River, Jordan. Appl. Sci. 2021, 11, 8638. https:// doi.org/10.3390/app11188638

Academic Editors: Amanda Laca Pérez and Yolanda Patiño.

Received: 6 August 2021

Accepted: 4 September 2021

Published: 17 September 2021

Publisher's Note: MDPI stays neutral with regard to jurisdictional claims in published maps and institutional affiliations.

Copyright: (c) 2021 by the authors. Licensee MDPI, Basel, Switzerland. This article is an open access article distributed under the terms and conditions of the Creative Commons Attribution (CC BY) license (https:// creativecommons.org/licenses/by/ $4.0 /)$.

\begin{abstract}
Assamra wastewater treatment plant (WWTP) is the largest treatment facility in Jordan. Treated wastewater is discharged into the Zarqa River (ZR) and used to irrigate fodder and vegetables. $\mathrm{ZR}$ also includes surface runoff, stormwater, and raw wastewater illegally discharged into the river. This study examined pharmaceutically active compounds (PhAC) in water resources in the ZR basin. Samples of WWTP influent and effluent and river water from four sites along ZR were collected. Concentrations of 18 target antibiotics, one stimulant, and 15 other PhACs were determined in the samples. Five antibiotics were detected in WWTP influent (510-860 ng L ${ }^{-1}$ for $\sum$ Antibiotics) and six in the effluent (2300-2600 $\mathrm{ng} \mathrm{L}^{-1}$ for $\sum$ Antibiotics). Concentrations in the effluent of all antibiotics except clarithromycin increased by 2 - to 5 -fold compared with those in influent, while clarithromycin concentration decreased by around 4- fold (from 308 to $82 \mathrm{ng} \mathrm{L}^{-1}$ ). WWTP influent and effluent samples contained 14 non-antibiotic PhACs, one simulant, and six antibiotics at detectable concentrations. The dominant PhACs were paracetamol (74\% of $\left.\sum \mathrm{PhACs}\right)$ in the influent and carbamazepine (78\% of $\sum$ PhACs) in the effluent. At ZR sampling sites, carbamazepine was the dominant PhAC in all cases (800-2700 ng L $\left.{ }^{-1}\right)$. The antibiotics detected in WWTP effluent were also detected at the ZR sites. In summary, water in ZR is contaminated with PhACs, including antibiotics, and wastewater discharge seems to be the main pathway for this contamination. The occurrence of antibiotics and other PhACs in the irrigated soil requires investigation to assess their fate.
\end{abstract}

Keywords: Assamra WWTP; caffeine; carbamazepine; irrigation; ofloxacin; paracetamol; pharmaceuticals; Zarqa River

\section{Introduction}

Worldwide, there is large-scale production and use of a vast range of pharmaceutically active compounds (PhACs), including antibiotics. Different regions of the world have different levels of restriction on prescription and sales of drugs. In Jordan, self-medication is common practice, and drugs can easily be purchased from drugstores without prior prescription, despite laws prohibiting the sale and dispensing of non-prescribed antibiotics [1,2]. In the study by Almaaytah et al. [2], more than 70\% of drugstores investigated dispensed antibiotics, without prescription, for medical issues that included sore throat, urinary tract infection, diarrhea, and otitis media. Antibiotic resistance genes in different types of bacteria have been reported in isolates from the human population in Jordan [3,4].

After ingestion, PhACs (including antibiotics, stimulants, and illicit drugs) and their metabolites end in human excreta (urine and faeces) and reach the environment via direct discharge or discharge of treated effluents from municipal wastewater systems [5,6]. Many low and middle-income countries host pharmaceutical industries that produce wastewater, which often receives poor treatment, e.g., ending up in the environment or discharged into municipal sewage systems [7-9]. For effective removal of PhACs from wastewater, tertiary treatment steps involving nanotechnologies, adsorption, membrane technologies, 
or advanced oxidation processes ( $\mathrm{UV}, \mathrm{H}_{2} \mathrm{O}_{2}$, photooxidation) are needed [10-13]. These technologies are generally expensive and demand significant resources for maintenance and operation. In many parts of the world, wastewater treatment facilities are overloaded, compromising the treatment efficiency, or not applying a tertiary treatment [14-17]. Consequently, effluents from WWTP constitute a significant source of PhACs, which lead to pollution of water resources, e.g., surface, ground, and lake water upon discharge.

Pollution of water resources with PhACs has been reported around the world. Still, most of the research focusing on these pollutants had been conducted in industrial and high-income countries, e.g., Japan, Europe, and the USA [9,18-24].

In Jordan, a middle-income country in the Mediterranean, wastewater treatment often does not include a tertiary step, and drug prescriptions and sales regulations are not regulated strictly. According to the Ministry of Water and Irrigation, 29 wastewater treatment plants (WWTPs) operate in Jordanian cities, with an estimated annual treated discharge of around $120 \mathrm{Mm}^{3}$ of wastewater [25]. The Assamra plant is the largest of Jordan's 29 WWTPs, treating wastewater from more than two million people, mainly in the Amman and Zarqa Governorates [26]. Government and non-government agencies in Jordan are currently promoting the reuse of treated wastewater to mitigate the chronic water shortage in the country and for nutrient recovery, i.e., recycling of phosphorus from sewage back to arable land. As a result, more than $92 \%$ of the treated wastewater produced in the main cities in Jordan, i.e., Amman and Zarqa, is used for irrigation [25], mainly in the Zarqa River basin.

The Zarqa River (ZR) is an ecosystem component of great importance for food supply and socioeconomic development in Jordan, as the river water is used to irrigate a wide range of vegetables, fodder crops, and industrial/cash crops in surrounding fields and gardens. The remaining ZR water flows down into King Talal Reservoir, a major water reservoir feeding King Abdullah Canal, from which water is taken for irrigation in the lower Jordan valley [26]. The annual average flow rate in ZR is around $360,000 \mathrm{~m}^{3} \mathrm{day}^{-1}$. Concerning water sources, $\mathrm{ZR}$ receives more than $325,000 \mathrm{~m}^{3}$ day $^{-1}$ of treated effluent from Assamra WWTP and surface water from Amman, Zarqa, Jerash, and parts of Mafraq [26]. Due to the large amounts of wastewater effluent discharged into $Z R$, the river can be assumed to be a significant pathway for spreading $\mathrm{PhACs}$ into the environment through its use as a source of irrigation water. Pollution with several types of micropollutants, including pesticides and pharmaceuticals, in different water sources in the lower Jordan River has been reported by Tiehm et al. [27], Tiehm et al. [28], and Zemann et al. [29]. A recent study detected 14 PhACs in influent and effluent of Assamra WWTP [30]. However, the pollution loads and fate of PhACs in river water along ZR have not been sufficiently explored, and more research is needed in this region.

This study aimed to determine the PhACs pollution of water resources in Jordan's ZR basin, an example of a low-middle income country. Specific objectives were (i) to determine the occurrence and concentrations of 33 multiclass PhACs (e.g., anti-inflammatory, beta-blockers, antibiotics, anti-diabetics, heart and vascular disease drugs, anti-epileptics, stimulants, and anti-fungal) in wastewater and water resources feeding ZR; and (ii) to investigate the contribution of Assamra WWTP to PhAC levels in ZR water and assess the performance of the WWTP in removing selected PhACs, including antibiotics.

\section{Materials and Methods}

\subsection{Description of the Study Area}

Wastewater and water resources contributing to the flow in ZR were studied. A catchment area of $4120 \mathrm{~km}^{2}$ located in the north of Jordan contributes to the natural streamflow in ZR [31]. The ZR Basin has an arid climate in the east and the southeast. In contrast, the western parts have typical Mediterranean climates that are semiarid in Amman (Capital of Jordan) and dry sub-humid in Ajloun, where rainfall exceeds $560 \mathrm{~mm}$. The western parts are mountainous and characterized by cool temperatures in winter and mild temperatures in summer. The annual rainfall ranges from more than $500 \mathrm{~mm}$ 
in the northwest to less than $100 \mathrm{~mm}$ in the east, with an average annual precipitation of $250 \mathrm{~mm}$ [32]. The basin hosts $60 \%$ of Jordan's population and $85 \%$ of all industries in Jordan, and its flood plain is used for agriculture [32]. The water downstream in ZR includes treated effluent from Assamra WWTP and surface runoff and stormwater generated during the rainy season (December-April) [33]. Assamra WWTP treats an average of $365,000 \mathrm{~m}^{3}$ day $^{-1}$ of municipal wastewater and industrial wastewater for the population of 2,270,000-3,300,000 $\mathrm{PE}$ [33,34]. The primary use of ZR water is irrigation fodder and vegetable crops in fields within the ZR flood plain [32]. This study area was also investigated in our previous study, and more details of the area can be found in Shigei et al. [35].

\subsection{Sample Collection}

In a single sampling event, wastewater and river water samples were collected in the ZR catchment area (Figure 1). The samples of influent and effluent were collected at Assamra WWTP $(n=4)$. River water samples were collected manually from the top $30 \mathrm{~cm}$ water layer of the river by filling high-density polyethylene (HDPE) plastic bottles from the center of the river at four locations: (i) Sukhna station (5.45 km from the main ZR), in a tributary unaffected by Assamra WWTP $(n=2)$; (ii) Twahin Eledwan station $(28.74 \mathrm{~km}$ from Assamra WWTP) $(n=2)$ and (iii) Military station ( $47.73 \mathrm{~km}$ from Assamra WWTP) $(n=2)$, both downstream of Assamra WWTP; and (iv) Jerash stream, a groundwater stream feeding into ZR $(n=2)$ (Figure 1, Table S1 in Supporting Information (SI)). Two samples were collected from each site, with an interval of $1 \mathrm{~h}$ between the samples. All samples were kept frozen at $-20^{\circ} \mathrm{C}$ and transported to Sweden for analysis of PhACs.

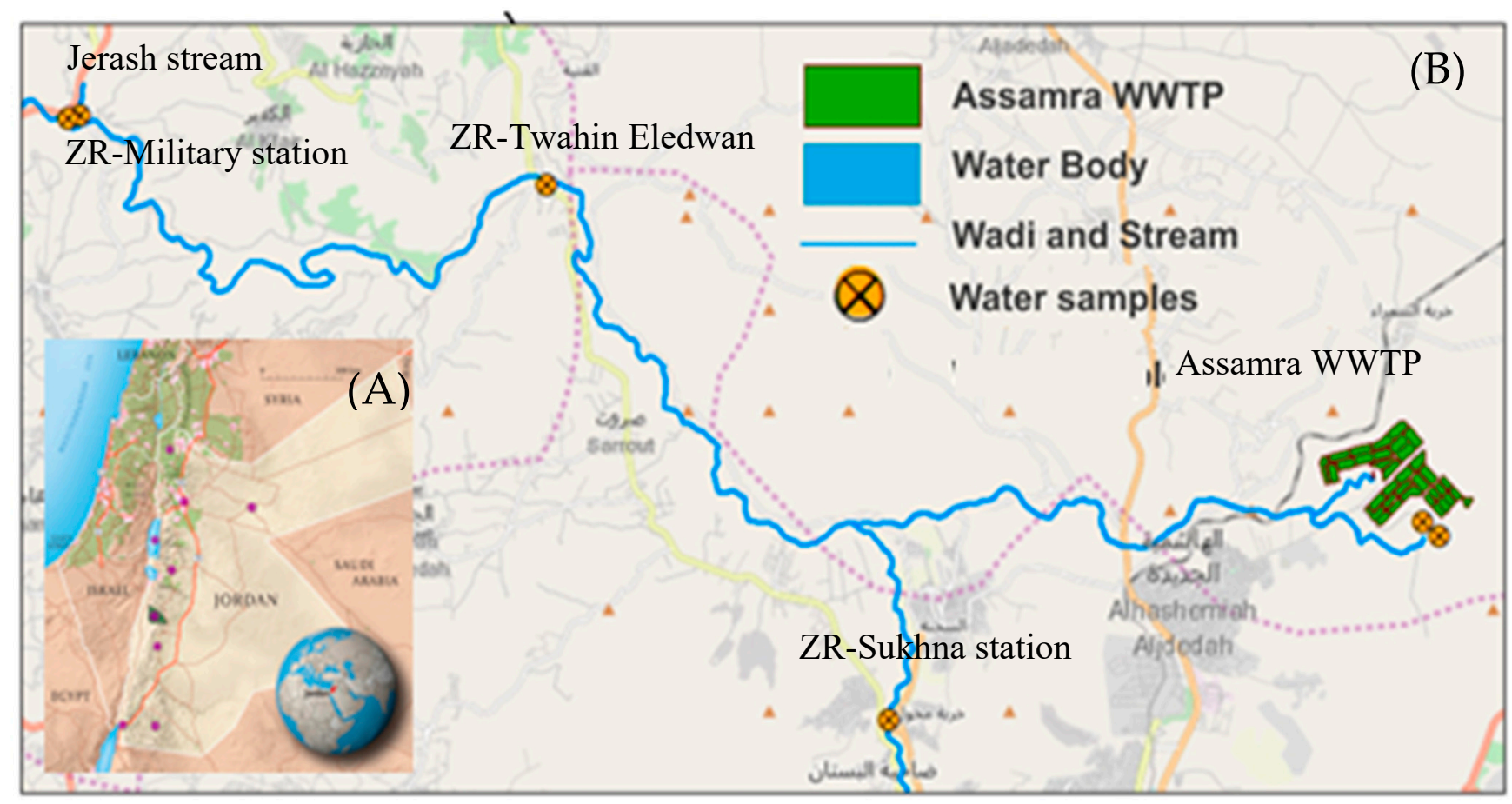

Figure 1. (A) Location of the Zarqa River (ZR) basin in Jordan. (B) Sampling sites for Assamra wastewater treatment plant (WWTP) influent and effluent $(n=4)$ and for river water at Sukhna station $(n=2)$, Twahin Eledwan station $(n=2)$, Military station $(n=2)$, and Jerash stream $(n=2)$. Part A of the diagram is modified from Shigei et al. (2020).

\subsection{PhACs Target Analyses}

The term PhACs is used hereafter to refer to all substances which have therapeutic effects other than antibiotics. Antibiotics were considered separately because of potential health and environmental impacts. A total of $15 \mathrm{PhACs}$ were included in the analysis (atenolol, amlodipine, bisoprolol, carbamazepine, citalopram, diazinon, fluoxetine, keto- 
conazole, metformin, metoprolol, oxazepam, paracetamol, propranolol, risperidone, and sertraline). In addition, the concentrations of 18 antibiotics (ciprofloxacin, clarithromycin, clindamycin, doxycycline, erythromycin, ofloxacin, linezolid, metronidazole, moxifloxacin, norfloxacin, tetracycline, trimethoprim, amoxicillin, ampicillin, benzylpenicillin, fusidic acid, rifampicin, and sulfamethoxazole) and one stimulant (caffeine) were analysed. The chemical properties of each compound are shown in Table S1. Isotopically labelled internal standards (IS) used in the analyses were diclofenac ${ }^{13} \mathrm{C}_{6}$, hydrochlorothiazide ${ }^{13} \mathrm{C}_{6}$, carbamazepine ${ }^{13} \mathrm{C}^{15} \mathrm{~N}$, and ibuprofen-d3.

\subsection{Extraction and Analyses of PhACs and Other Parameters}

All influent, effluent, and river water samples were extracted using solid-phase extraction with Oasis HLB cartridges (200 mg, 6 cc; Waters Corporation, Manchester, UK) according to the extractions method previously described in Dalahmeh et al. [36], Dalahmeh et al. [37], nd Gros et al. [38]. Before extraction, the samples were spiked with $100 \mu \mathrm{L}$ of IS mixture containing $1 \mathrm{ng} \mu \mathrm{L}^{-1}$ diclofenac ${ }^{13} \mathrm{C}_{6}$, hydrochlorothiazide ${ }^{13} \mathrm{C}_{6}$, carbamazepine ${ }^{13} \mathrm{C}^{15} \mathrm{~N}$, and ibuprofen- $\mathrm{d}_{3}$.

The mass of the target PhACs, antibiotics, and caffeine compounds was determined using high-performance liquid chromatography coupled with mass spectrophotometry (HPLC-MS/MS). All analyses were carried out at the Swedish Environmental Institute (IVL) laboratories using a binary Shimadzu AD20 UFLC HPLC system with automatic sample changer and column furnace coupled to an ABSciex API-4000 mass spectrometer. Samples were analysed under positive and negative electrospray ionization (ESI) mode using a Waters XBridge BEH C18 column (100 $\mathrm{mm} \times 2.1 \mathrm{~mm}$ with $3 \mu \mathrm{m}$ opening size). The eluents used in the mobile phase were A: $10 \mathrm{mM}$ acetic acid in deionized water and B: methanol. The gradient used was a linear gradient from 0-90\% methanol for $17 \mathrm{~min}$, with a final plateau at $90 \%$ methanol for $4 \mathrm{~min}$ before a rapid return to $100 \% \mathrm{~A}$ and a final recovery and equalization of $2 \mathrm{~min}$. The concentration of each analyte was quantified using an eight-point calibration curve $(0,5,10,20,50,100,200$, and $500 \mathrm{ng})$.

Besides the target PhACs, antibiotics, and caffeine, the river water, influent and effluent samples were analysed for $\mathrm{pH}$, chemical oxygen demand (COD), electrical conductivity (EC), total suspended solids (TSS), and total solids (TS). All analyses of liquid samples were performed according to Standard Methods for Examination of Water and Wastewater APHA [39], using the following protocols: $\mathrm{pH}$ (4500-H and B), biochemical oxygen demand (BOD5; 5210-B), TSS, and TS (2540-B-D). The pH was measured by an electrode that measures the concentration of $\mathrm{H}$ ion by millivolts. The Chemical Oxygen Demand was measured by oxidizing the water sample by oxidizing agent (potassium dichromate) followed by open reflux digestion at $1500{ }^{\circ} \mathrm{C}$ for $2 \mathrm{~h}$, then back titration for the remaining dichromate using sodium thiosulfate. The electrical conductivity of water was measured using a conductivity cell immersed in a $50 \mathrm{~mL}$ sample. Total solid was measured by gravimetric method, through drying the sample in an oven at $105^{\circ} \mathrm{C}$ overnight until the crucible has a constant weight. Then, the difference in weights showed the total solids that exist in a sample (summation of total dissolved solids and total suspended solids). Total suspended solid was also measured by gravimetric method, by weighing the washed dried filter paper, then filtering the sample and drying it in an oven at $105^{\circ} \mathrm{C}$, the difference showing the concentration of suspended solids.

\subsection{Quality Control}

Method blank was prepared using $500 \mathrm{~mL}$ of pure MilliQ ${ }^{\circledR \circledR}$ water spiked with $100 \mu \mathrm{L}$ IS. The blank sample was extracted following the same procedure as used for the other liquid samples. The blank sample did not show detectable levels of any of the measured substances. All detectable concentrations lower than $1 \mathrm{ng} \mathrm{L}{ }^{-1}$ were recorded as $<1 \mathrm{ng} \mathrm{L}{ }^{-1}$. 


\subsection{Calculations and Statistical Analysis}

Analysis of variance (ANOVA) at 95\% confidence level was used to assess the significance of the difference in PhAC concentrations between the different locations. All statistical analyses were performed using the ANOVA adds-in package coupled to Excel 2016 (Microsoft Office, Microsoft, USA).

\section{Results and Discussion}

\subsection{General Quality of Wastewater and Water Resources within Zarqa River Basin}

The influent to Assamra WWTP contained $1550 \mathrm{mg} \mathrm{L}^{-1}$ of TS, of which $33.5 \%$ was in suspended form, i.e., as TSS (Table S3 in SI). Organic matter content (expressed as COD) was high in influent samples $\left(950 \mathrm{mg} \mathrm{L}^{-1}\right)$. Comparison of influent and effluent concentrations indicated that Assamra WWTP was efficient in TSS and COD removal (98\% and $96 \%$ ). At all sampling locations, along with ZR, the TSS concentrations were low (<2-40 $\mathrm{mg} \mathrm{L}^{-1}$ ) (Table S3), while the TS concentrations were high $\left(840-4600 \mathrm{mg} \mathrm{L}^{-1}\right)$. Jerash stream contained the highest TS concentration $\left(4600 \mathrm{mg} \mathrm{L}^{-1}\right)$ and had visible white residue. Organic matter content in river water was low $\left(4-30 \mathrm{mg} \mathrm{L}^{-1}\right)$ at all sampling locations except Sukhna station, which seemed to have minor contamination with organic matter (110 mg COD L $\left.{ }^{-1}\right)$. A wastewater pumping station is located upstream of Sukhna station, and leakages of wastewater would flow downstream to Sukhna station.

\subsection{Concentration and Removal of PhACs and Antibiotics in Assamra WWTP}

A total of $15 \mathrm{PhACs}$ (excluding antibiotics) and one stimulant were detected in influent and effluent of Assamra WWTP. The combined concentration of PhACs (excluding antibiotics and caffeine; $\sum \mathrm{PhACs}$ ) was 20,668-31,485 $\mathrm{ng} \mathrm{L}^{-1}$ in the influent and 4032-4394 $\mathrm{ng} \mathrm{L}^{-1}$ in the effluent, showing a significant reduction effect of treatment in Assamra WWTP (Figure 2, Table S4 in SI). The influent contained high levels of caffeine $\left(27,737-53,223 \mathrm{ng} \mathrm{L}^{-1}\right.$ ), but these were reduced effectively in Assamra WWTP, resulting in a concentration of 64-273 ng L ${ }^{-1}$ in the effluent. Caffeine is highly biodegradable and can be used as an indicator of residual bioactivity [40].

The dominant PhACs in influent were paracetamol (anti-inflammatory; 14,891-24,309 $\mathrm{ng} \mathrm{L}^{-1}$ ) which comprised $74 \%$ of $\sum \mathrm{PhACs}$, carbamazepine (anti-epileptic; $2365-3020 \mathrm{ng} \mathrm{L}^{-1}$ ), which comprised $11 \%$ of $\sum \mathrm{PhACs}$, atenolol (beta-blocker; $1723-1952 \mathrm{ng} \mathrm{L}^{-1}$ ), which comprised $7 \%$ of $\sum \mathrm{PhACs}$, and metformin (anti-diabetic), which comprised $4 \%$ of $\sum \mathrm{PhACs}$. In the effluent, carbamazepine was the dominant PhAC (3138-3352 $\mathrm{ng} \mathrm{L}^{-1}$ ), comprising $78 \%$ of $\sum \mathrm{PhACs}$, followed by metoprolol (beta-blocker; $10 \%$ of $\sum$ PhACs). The removal rate of the dominant substances during WWTP treatment was: $99 \%$ for paracetamol, $-22 \%$ for carbamazepine, $95 \%$ for atenolol, and $97 \%$ metformin (Figure 3). Poor removal has been reported previously for carbamazepine and hydrochlorothiazide in WWTPs in Spain [41]. Lajeunesse et al. also reported poor removal of carbamazepine in WWTPs in Canada [42]. Other studies investigating the removal of PhACs in middle-income countries (e.g., Jordan) report low removal efficiencies $(<50 \%)$ for a number of PhACs, including carbamazepine [30]. Bisoprolol (beta-blocker) was present in higher effluent concentrations than influent (10-fold increase). Beta-blocker i.e bisoprolol is generally difficult to remove from wastewater [43]. The overall removal rate in Assamra WWTP was $81 \%-87 \%$ for $\sum$ PhACs and $99 \%$ for caffeine. The concentrations of all measured substances are shown in Table S4.

In a previous study, Al-Mashaqbeh et al. [30] found that carbamazepine concentration was high in Assamra WWTP influent $\left(1100 \mathrm{ng} \mathrm{L}^{-1}\right)$ and effluent $\left(850 \mathrm{ng} \mathrm{L}^{-1}\right)$, resulting in low removal of the substance $(23 \%)$. That study also reported a high occurrence of caffeine (156,000 $\left.\mathrm{ng} \mathrm{L}^{-1}\right)$ and its metabolite (1,7-dimethylxanthine; 10,500 $\mathrm{ng} \mathrm{L}^{-1}$ ) in influent, but high removal in Assamra WWTP plant (>99\%), and very high concentrations $\left(36,700 \mathrm{ng} \mathrm{L}^{-1}\right)$ of paracetamol in influent, but efficient removal in the WWTP $(99 \%)$. The results in the present study confirm these findings of Al-Mashaqbeh et al. [30]. 


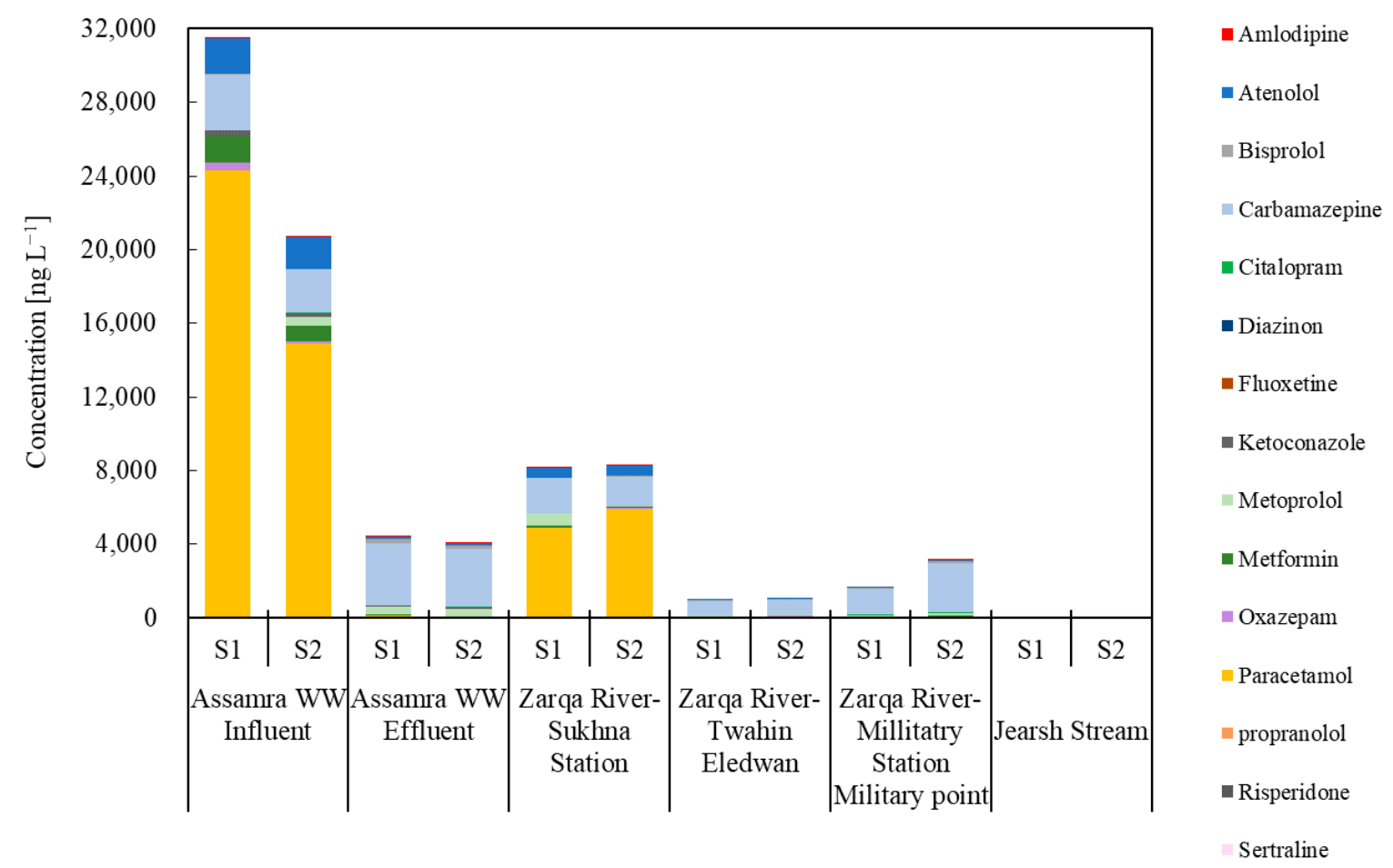

Figure 2. Concentrations (ng L ${ }^{-1}$ ) of pharmaceutically active compounds (PhACs, excluding antibiotics) in Assamra wastewater treatment plant (WWTP) influent $(n=2)$ and effluent $(n=2)$, and in water from the Zarqa River at Sukhna station, $(n=2)$, Twahin Eledwan station $(n=2)$, Military station $(n=2)$ and Jerash stream $(n=2)$. S1, S2 = parallel samples.

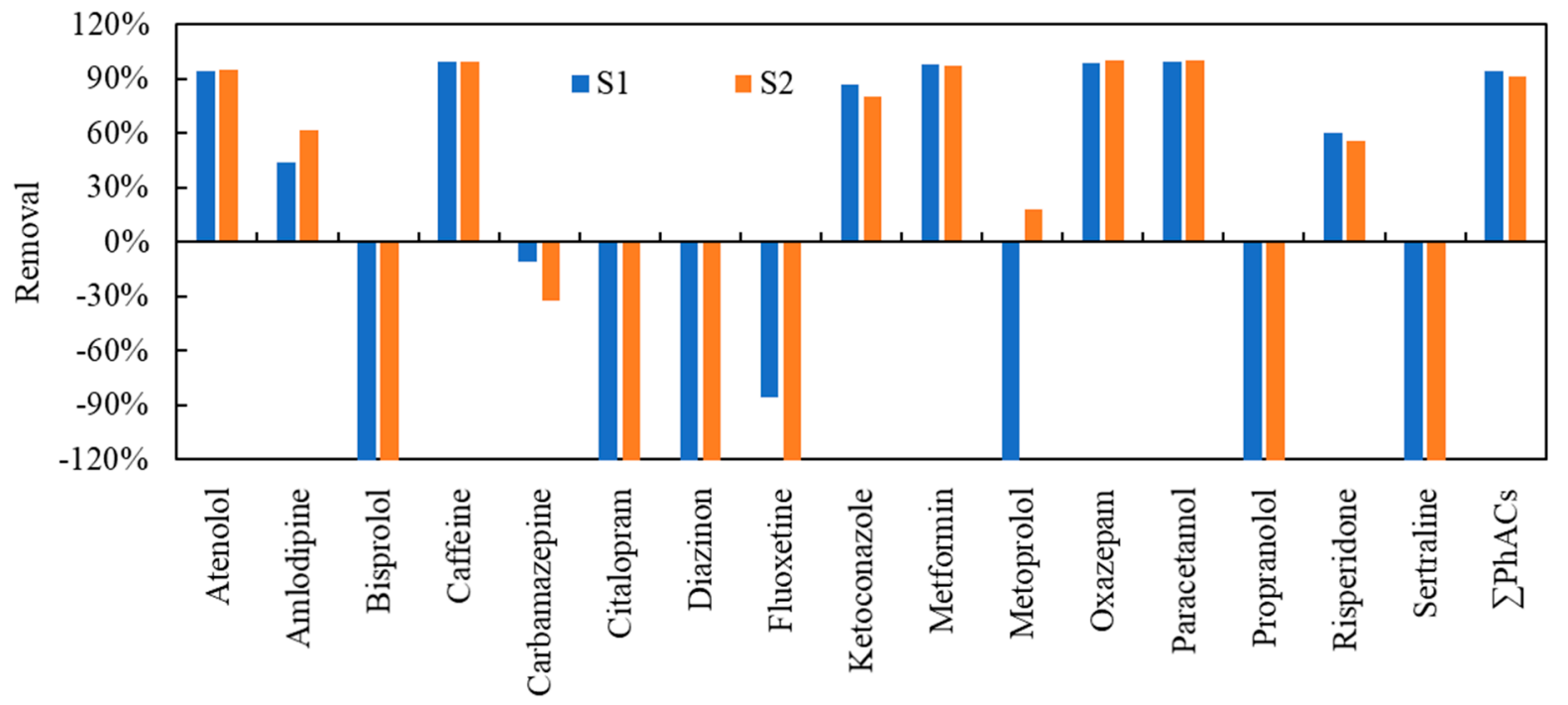

Figure 3. Efficiency (\%) of Assamra wastewater treatment plant in removing pharmaceutically active compounds (PhACs, excluding antibiotics) from the wastewater. S1, S2 = parallel samples.

Of the 18 antibiotics targeted in the analysis, only five substances were detected in the influent and six in the effluent of Assamra WWTP. These were clarithromycin, erythromycin, ofloxacin, metronidazole, and sulfamethoxazole in the influent, and these five plus ciprofloxacin in the effluent (Figure 4). Ofloxacin (fluoroquinolones class) showed the highest concentration in wastewater effluent, followed by erythromycin (macrolides class) and metronidazole (antiprotozoal class) (Figure 4, Table S5 in SI). None of the target substances in the penicillin class (amoxicillin, ampicillin, benzylpenicillin) was detected in the influent or effluent samples. This result is surprising since Almaaytah et al. [2] reported 
that antibiotics in the classes fluoroquinolones, macrolides, penicillin, and antiprotozoal are the most commonly dispensed antibiotics in Jordan.

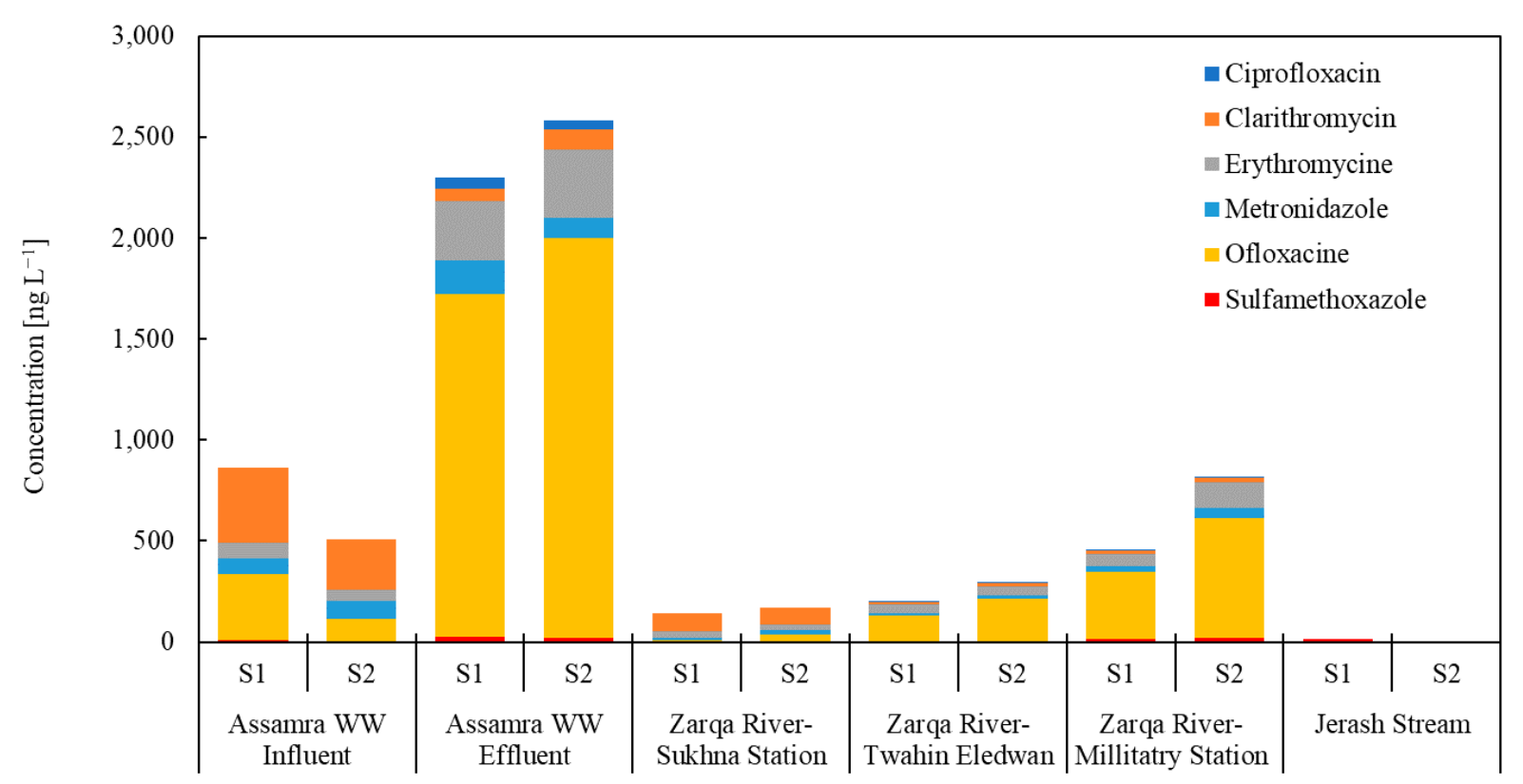

Figure 4. Concentrations of antibiotics $\left(\mathrm{ng} \mathrm{L}^{-1}\right)$ in Assamra wastewater treatment plant (WWTP) influent $(n=2)$ and effluent $(n=2)$, and in water from the Zarqa River at Sukhna station, $(n=2)$, Twahin Eledwan station $(n=2)$, Military station $(n=2)$, and Jerash stream $(n=2) . \mathrm{S} 1$, S2 = parallel samples.

The combined antibiotics ( $\sum$ Antibiotics) concentration was $510-860 \mathrm{ng} \mathrm{L}^{-1}$ in influent and 2300-2600 $\mathrm{ng} \mathrm{L}^{-1}$ in the effluent (Figure 4, Table S5). After passing through the treatment process, only the concentration of clarithromycin decreased (from 308 to $82 \mathrm{ng} \mathrm{L}^{-1}$; removal rate $73 \%$ on average). C.F. Couto et al. reviewed the WWTPs performances to remove the PhACs in various countries [44]. The reported studies of 12 kinds of antibiotics, including Ofloxacin and Erythromycin, all observed positive values as removal ratio. However, the present study showed 2- to 5-fold higher concentrations of all other antibiotics in effluent than the levels in influent. Ciprofloxacin, which was not detected in the influent, was found in the effluent samples. Hydrolyses of organic matter of wastewater of solid phase and hence the release of ciprofloxacin bound to solids into the liquid phase could have occurred, explaining the increase of the substance in the effluent. Moreover, antibiotics partition into water is generally based on the chemical and physical properties of the antibiotic itself [45]. For example, clarithromycin has high partition coefficients $(\log$ Kow $=3.16, \operatorname{Koc}=150$, Table S2) and low solubility. These properties suggest that clarithromycin is likely to adsorb to the solids in wastewater, which explains this substance's reduction. In contrast, ofloxacin has low $\log$ Kow $(-2)$ and high-water solubility $\left(6.7 \times 105 \mathrm{mg} \mathrm{L}^{-1}\right)$ (Table S2), suggesting that it is water-soluble, explaining the high concentrations in the effluent.

In this study, we did not analyse the concentrations of antibiotics in the solid phase of raw wastewater or the WWTP sludge. It is likely that a fraction of the antibiotics initially partitioned to organic matter or accumulated in biomass in the wastewater was released after hydrolysis of the organic matter during biological treatment in the WWTP. This condition would partly explain the increase in antibiotic concentrations in effluent compared with influent, as also suggested in other studies $[45,46]$. Another explanation could be the presence of antibiotic conjugates or metabolites, which were cleaved back to their mother forms during the treatment process [46,47]. 


\subsection{Spatial Distribution of PhACs and Antibiotics in ZR}

At Sukhna station, on a tributary not impacted by Assamra WWTP effluent, $\sum$ PhACs were 8141-8178 $\mathrm{ng} \mathrm{L}^{-1}$ (Figure 2, Table S4). The high concentration of PhACs at this site was attributed to wastewater contamination and possible leakages of untreated wastewater from a pumping station upstream of Sukhna station. In addition, a small peri-urban community discharges its wastewater to the river, and sewage tankers illegally dump sewage close to the river. These are potential reasons for the high $\sum \mathrm{PhAC}$ in river water at Sukhna station.

The Twahin Eledwan station sampling site downstream of Assamra WWTP showed lower levels of $\sum$ PhACs (970-1033 ng L ${ }^{-1}$ ) than in WWTP effluent (4032-4394 $\mathrm{ng} \mathrm{L}^{-1}$ ). The dilution of PhACs can explain this, with surface runoff in the river channel. Thereafter, the concentration of $\sum \mathrm{PhACs}$ increased along the flow path in $\mathrm{ZR}$ and reached its highest level at Military station (1657-3154 $\mathrm{ng} \mathrm{L}^{-1}$ ) (Figure 1). Thus, there are evidently notable side-inputs of PhACs from areas surrounding the river. In particular, a military facility located downstream seems to be a point source of PhACs to ZR (Figures 3 and 4). In Jerash stream, a small downstream tributary of ZR, surface water samples showed low detectable deficient levels of $\sum \mathrm{PhACs}\left(<3 \mathrm{ng} \mathrm{L}^{-1}\right)$. The source of this tributary is spring water, and our sampling site was located just before the spring water flow mixed with other water from ZR.

It should be mentioned that the concentrations of individual PhACs differed significantly between all sampling sites. Paracetamol was detected at all sites but occurred in the highest concentrations at Sukhna station (4870-5900 $\left.\mathrm{ng} \mathrm{L}^{-1}\right)$. Paracetamol concentration then decreased to reach $40-70 \mathrm{ng} \mathrm{L}^{-1}$ as the water flowed downstream in ZR due to dilution and probable degradation. Carbamazepine was the dominant PhAC at all sites upstream and along ZR (800-2700 $\mathrm{ng} \mathrm{L}^{-1}$ ). Interestingly, we found a negative correlation between the concentration of carbamazepine and TSS content in water samples, i.e., the concentration of carbamazepine in water decreased as the TSS content in the water increased. Adsorption of carbamazepine to river sediment has been reported elsewhere [48,49]. Metoprolol and bisoprolol were among the dominant PhACs detected in ZR water.

The six antibiotic substances detected in Assamra WWTP effluent (clarithromycin, erythromycin, ofloxacin, metronidazole, sulfamethoxazole, and ciprofloxacin) were also detected in water at the different sampling sites along with ZR (Figure 4). Ofloxacin showed the highest concentrations in all sites along with $\mathrm{ZR}$, and its concentration increased downstream in the river to reach the highest level at Military station (334-595 $\left.\mathrm{ng} \mathrm{L}^{-1}\right)$. It is not clear why this was the case. Still, we cannot exclude desorption of previously sorbed antibiotics from river sediment to water and illegal dumping of sewage sludge as contributing causes. Other studies have found that antibiotics (specifically sulfamethoxazole) decompose during transport within water systems [50]. In addition, the present study has shown the results of one-time sampling, but the river flow rate is subjected to seasonal change that would affect the concentration and retention time of the PhACs [51]. Therefore, more monitoring campaigns are recommended for future work.

The estimated mass flow of target substances in ZR water at Military station was 39-71 kg year ${ }^{-1}$ for antibiotics and 60-110 $\mathrm{kg}_{\text {year }}{ }^{-1}$ for other PhACs, based on water flow of $86 \times 106 \mathrm{~m}^{3}$ year $^{-1}$. It should be pointed out that most of the water in ZR is used for the irrigation of vegetables and fodder crops [35]. The fate of antibiotics and other PhACs in irrigated soils in the study area was not analysed in this study. However, the transport of antibiotics within the ZR water system is alarming and there is likelihood that it poses a risk of developing and spreading antimicrobial resistance within the area. Upstream measures might be needed to reduce antibiotics in wastewater and limit the loads entering the water system and the environment. Such measures could include limiting the prescription and sale of antibiotics and increasing awareness among the public and pharmacists of the consequences of antimicrobial resistance. 


\section{Conclusions}

This study examined the occurrence of 15 pharmaceutically active compounds (PhACs), 18 antibiotics, and one stimulant (caffeine) in influent and effluent from Assamra WWTP and in water samples from the Zarqa River and its tributaries. Based on the results obtained, the following conclusions were drawn:

- Assamra WWTP is efficient in minimising the concentrations of PhACs and caffeine, with an overall efficiency of $81-87 \%$ and $99 \%$, respectively. It is inefficient in removing bisoprolol and carbamazepine, for which effluent concentrations were $128 \%$ and $22 \%$ higher than influent.

- Assamra WWTP is inefficient in removing antibiotics from wastewater, as concentrations of all antibiotics detected, except clarithromycin, increased by 2 - to 5 -fold in the effluent compared with the influent.

- Zarqa river water is contaminated with antibiotics and PhACs. Sources of these contaminants are likely to be effluent from Assamra WWTP and side-inputs from the areas surrounding the river.

- $\quad \sum$ Antibiotics and $\sum$ PhACs in Zarqa river water are still lower than those in Assamra WWTP effluent. Dilution, degradation, evaporation, and adsorption are potential mechanisms contributing to lowering the concentration of PhACs along the river.

- $\quad$ Since most Zarqa river is used for irrigation of vegetables and fodder crops, the PhACs and antibiotics in river water could enter the food chain and pose a risk of spreading antibiotic-resistant genes and mobile genetic elements (i.e., plasmids and integrin). Further research is required to study the fate of antibiotics and other PhACs in irrigated soils, WWTP sludge, and plants in the Zarqa river basin.

- Future research should aim at conducting more sampling and at staging analysis at different seasons to understand the effects of weather conditions on the fate of PhACs in the study area. In addition, analyses of the PhACs in the solid phase (i.e., sludge) are necessary to understand the partitioning of the PhACs between the water and solid phases of the wastewater in the Assamra plant and to evaluate the total loads of PhACs in the wastewater influent and effluent.

Supplementary Materials: The following are available online at https:/ / www.mdpi.com/article/10 .3390/app11188638/s1, Table S1. Geographic positioning system (GPS) coordinates of the sampling sites for wastewater treatment plant (WWTP) influent and effluent and Zarqa River (ZR) water. Data from [35], Table S2. List of pharmaceutically active compounds (PhACs, including antibiotics) targeted in analysis of liquid samples and their chemical and physical properties (chemical formula, molecular weight (MW), logarithmic octanol-water distribution coefficient (log Kow), organic carbonwater partition coefficient (Koc), logarithmic dissociation constant (pKa), and water solubility at $25{ }^{\circ} \mathrm{C}(\mathrm{mg} / \mathrm{L})$. Values without any reference superscript $(+)$ were modeled and taken from ChemSpider (2020), Table S3. Concentrations of total suspended solids (TSS), total solids (TS) and chemical oxygen demand (COD) samples ( $\mathrm{n}=1$ per site) in Assamra wastewater treatment plant (WWTP) influent and effluent and Zarqa River (ZR) water at Sukhna station, Twahin Eledwan station, Military station, and Jerash stream. Data from [35].

Author Contributions: The authors had contributed to the published work according to the following description: M.S.: conducted the laboratory analyses, the statistical analyses and revised the manuscript according to reviewers input; A.A.: participated in design and planning of the study; A.H.: participated in describing and visualizing the study area, S.S.D.: planned the study, collected the samples, participated in data analyses and wrote the manuscript. All authors have read and agreed to the published version of the manuscript.

Funding: The study was funded by the Swedish Research Council (FORMAS) through grant 1692013-1963 for the project "Pharmaceutical Pollution at Use of Wastewater in Crop Production" and the Swedish Foundation for international cooperation in research and education (grant number PT2016-6875).

Data Availability Statement: Original data are presented in the supporting information. 
Acknowledgments: Special thanks to Raed Jaber, Samir Tawalbeh, and Mohamed Mashatleh at the Royal Scientific Society of Jordan for their assistance in sample collection and facilitating the shipping of samples to Sweden. Thanks also to members of the Water Quality Laboratory at the Royal Scientific Society of Jordan for their efforts in physical and chemical analyses of the samples. Instrumental identification of the pharmaceuticals was performed at the Swedish Environmental Institute (IVL), Stockholm. Special thanks to Gunnar Thorsén for his effort in the analytical procedures.

Conflicts of Interest: The authors have no competing interest to declare, or financial or personal relationships with other people or organizations that could have inappropriately influenced this work.

\section{References}

1. Al-Azzam, S.I.; Al-Husein, B.A.; Alzoubi, F.; Masadeh, M.M.; Al-Horani, M.A.S. Self-medication with antibiotics in Jordanian population. Int. J. Occup. Med. Environ. Health 2007, 20, 373-380. [CrossRef]

2. Almaaytah, A.; Mukattash, T.L.; Hajaj, J. Dispensing of non-prescribed antibiotics in Jordan. Patient Prefer. Adherence 2015, 9 , 1389-1395. [CrossRef]

3. Nimri, L.F.; Batchoun, R. Community-acquired bacteraemia in a rural area: Predominant bacterial species and antibiotic resistance. J. Med. Microbiol. 2004, 53, 1045-1049. [CrossRef]

4. Shakhatreh, M.; Swedan, S.; Al-Odat, M.; Khabour, O. Uropathogenic Escherichia coli (UPEC) in Jordan: Prevalence of Urovirulence Genes and Antibiotic Resistance. J. King Saud Univ. Sci. 2018, 31, 648-652. [CrossRef]

5. Bijlsma, L.; Emke, E.; Hernández, F.; de Voogt, P. Investigation of drugs of abuse and relevant metabolites in Dutch sewage water by liquid chromatography coupled to high resolution mass spectrometry. Chemosphere 2012, 89, 1399-1406. [CrossRef]

6. $\quad$ Lindberg, R.; Östman, M.; Olofsson, U.; Grabic, R.; Fick, J. Occurrence and behaviour of 105 active pharmaceutical ingredients in sewage waters of a municipal sewer collection system. Water Res. 2014, 58, 221-229. [CrossRef]

7. D'Sa, S.; Patnaik, D. The Impact of the Pharmaceutical Industry of Hyderabad in the Pollution of the Godavari River. In Water Management in South Asia: Socio-Economic, Infrastructural, Environmental and Institutional Aspects; Bandyopadhyay, S., Magsi, H., Sen, S., Ponce Dentinho, T., Eds.; Contemporary South Asian Studies; Springer: Cham, Switzerland, 2020 ; pp. 23-51. ISBN 978-3-030-35237-0.

8. Kabdaşl1, N.; Olmez-Hanci, T.; Akgun, G.; Tunay, O. Assessment of Pollution Profile and Wastewater Control Alternatives of a Pharmaceutical Industry. Fresenius Environ. Bull. 2019, 28, 626-632.

9. Velpandian, T.; Halder, N.; Nath, M.; Das, U.; Moksha, L.; Gowtham, L.; Batta, S.P. Un-segregated waste disposal: An alarming threat of antimicrobials in surface and ground water sources in Delhi. Environ. Sci. Pollut. Res. Int. 2018, 25, 29518-29528. [CrossRef]

10. Garrido-Cardenas, J.A.; Esteban-García, B.; Agüera, A.; Sánchez-Pérez, J.A.; Manzano-Agugliaro, F. Wastewater Treatment by Advanced Oxidation Process and Their Worldwide Research Trends. Int. J. Environ. Res. Public. Health 2020, 17, 170. [CrossRef] [PubMed]

11. Ankush; Mandal, M.K.; Sharma, M.; Khushboo; Pandey, S.; Dubey, K.K. Membrane Technologies for the Treatment of Pharmaceutical Industry Wastewater. In Water and Wastewater Treatment Technologies; Bui, X.-T., Chiemchaisri, C., Fujioka, T., Varjani, S., Eds.; Energy, Environment, and Sustainability; Springer: Singapore, 2019; pp. 103-116. ISBN 9789811332593.

12. Rivadulla, E.; García-Fernández, I.; Romalde, J.; Fernandez-Ibanez, P.; Polo, D. Solar radiation and photo-Fenton systems: Novel applications for norovirus disinfection in water. In Noroviruses: Outbreaks, Control and Prevention Strategies; Nova Science Publishers: Hauppauge, NY, USA, 2017.

13. Sudeep, M.; Vinutha, M. Nanotechnology-As antibacterial and heavy metal removal in waste water treatment-A review. AIP Conf. Proc. 2018, 2039, 020067. [CrossRef]

14. Bougnom, B.P.; Zongo, C.; McNally, A.; Ricci, V.; Etoa, F.X.; Thiele-Bruhn, S.; Piddock, L.J.V. Wastewater used for urban agriculture in West Africa as a reservoir for antibacterial resistance dissemination. Environ. Res. 2019, 168, 14-24. [CrossRef]

15. Graham, D.W.; Giesen, M.J.; Bunce, J.T. Strategic Approach for Prioritising Local and Regional Sanitation Interventions for Reducing Global Antibiotic Resistance. Water 2019, 11, 27. [CrossRef]

16. Marathe, N.P.; Pal, C.; Gaikwad, S.S.; Jonsson, V.; Kristiansson, E.; Larsson, D.G.J. Untreated urban waste contaminates Indian river sediments with resistance genes to last resort antibiotics. Water Res. 2017, 124, 388-397. [CrossRef]

17. Reymond, P.; Abdel Wahaab, R.; Moussa, M.S.; Lüthi, C. Scaling up small scale wastewater treatment systems in low- and middle-income countries: An analysis of challenges and ways forward through the case of Egypt. Util. Policy 2018, 52, 13-21. [CrossRef]

18. Arya, G.; Tadayon, S.; Sadighian, J.; Jones, J.; de Mutsert, K.; Huff, T.B.; Foster, G.D. Pharmaceutical chemicals, steroids and xenoestrogens in water, sediments and fish from the tidal freshwater Potomac River (Virginia, USA). J. Environ. Sci. Health Part A Toxic Hazard. Subst. Environ. Eng. 2017, 52, 686-696. [CrossRef]

19. Burke, V.; Richter, D.; Greskowiak, J.; Mehrtens, A.; Schulz, L.; Massmann, G. Occurrence of Antibiotics in Surface and Groundwater of a Drinking Water Catchment Area in Germany. Water Environ. Res. Res. Publ. Water Environ. Fed. 2016, 88, 652-659. [CrossRef] 
20. Dodgen, L.K.; Kelly, W.R.; Panno, S.V.; Taylor, S.J.; Armstrong, D.L.; Wiles, K.N.; Zhang, Y.; Zheng, W. Characterizing pharmaceutical, personal care product, and hormone contamination in a karst aquifer of southwestern Illinois, USA, using water quality and stream flow parameters. Sci. Total Environ. 2017, 578, 281-289. [CrossRef]

21. Jurado, A.; Walther, M.; Díaz-Cruz, M.S. Occurrence, fate and environmental risk assessment of the organic microcontaminants included in the Watch Lists set by EU Decisions 2015/495 and 2018/840 in the groundwater of Spain. Sci. Total Environ. 2019, 663, 285-296. [CrossRef] [PubMed]

22. König, M.; Escher, B.I.; Neale, P.A.; Krauss, M.; Hilscherová, K.; Novák, J.; Teodorović, I.; Schulze, T.; Seidensticker, S.; Kamal Hashmi, M.A.; et al. Impact of untreated wastewater on a major European river evaluated with a combination of in vitro bioassays and chemical analysis. Environ. Pollut. 2017, 220, 1220-1230. [CrossRef]

23. Nishi, I.; Kawakami, T.; Onodera, S. Monitoring the concentrations of nonsteroidal anti-inflammatory drugs and cyclooxygenaseinhibiting activities in the surface waters of the Tone Canal and Edo River Basin. J. Environ. Sci. Health Part A Toxic. Hazard. Subst. Environ. Eng. 2015, 50, 1108-1115. [CrossRef]

24. Schimmelpfennig, S.; Kirillin, G.; Engelhardt, C.; Duennbier, U.; Nützmann, G. Fate of pharmaceutical micro-pollutants in Lake Tegel (Berlin, Germany): The impact of lake-specific mechanisms. Environ. Earth Sci. 2016, 75, 893. [CrossRef]

25. Directorate of Media and Water Awareness. The Annual Report of Ministry of Water and Irrigation; Ministry of Water and Irrigation (MWI): Amman, Jordan, 2018.

26. Al-Omari, A.; Farhan, I.; Kandakji, T.; Jibril, F. Pollution Sources to Zarqa River: Their Impact on the River Water Quality as a Source of Irrigation Water. 2017. Available online: http://mena.exceed-swindon.org/wp-content/uploads/2015/03/0025 -Abbas-Manuscript-Marakech-2018-02-27-final-pp.pdf (accessed on 3 September 2021).

27. Tiehm, A.; Schmidt, N.; Lipp, P.; Zawadsky, C.; Marei, A.; Seder, N.; Ghanem, M.; Paris, S.; Zemann, M.; Wolf, L. Consideration of emerging pollutants in groundwater-based reuse concepts. Water Sci. Technol. 2012, 66, 1270-1276. [CrossRef]

28. Tiehm, A.; Schmidt, N.; Stieber, M.; Sacher, F.; Wolf, L.; Hoetzl, H. Biodegradation of Pharmaceutical Compounds and their Occurrence in the Jordan Valley. Water Resour. Manag. 2011, 25, 1195-1203. [CrossRef]

29. Zemann, M.; Wolf, L.; Pöschko, A.; Schmidt, N.; Sawarieh, A.; Seder, N.; Tiehm, A.; Hötzl, H.; Goldscheider, N. Sources and processes affecting the spatio-temporal distribution of pharmaceuticals and X-ray contrast media in the water resources of the Lower Jordan Valley, Jordan. Sci. Total Environ. 2014, 488-489, 100-114. [CrossRef]

30. Al-Mashaqbeh, O.; Alsafadi, D.; Dalahmeh, S.; Bartelt-Hunt, S.; Snow, D. Correction: Almashaqbeh, O.; et al., Removal of Selected Pharmaceuticals and Personal Care Products in Wastewater Treatment Plant in Jordan. Water 2020, 12, 1122. [CrossRef]

31. Al-Omari, A.; Farhan, I.; Kandakji, T.; Jibril, F. Zarqa River pollution: Impact on its quality. Environ. Monit. Assess. 2019, 191, 166. [CrossRef]

32. Adaptation to Climate Change to Sustain Jordan's MDG Achievements; Ministry of Water and Irrigation (MWI): Amman, Jordan, 2013.

33. SUEZ. As Samra Wastewater Treatment Plant (Jordan); SUEZ: Amman, Jordan, 2019; p. 7.

34. Myszograj, S.; Qteishat, O. Operate of As-Samra Wastewater Treatment Plant in Jordan and Suitability for Water Reuse. Inż. Ochr. Śr. 2011, 14, 29-40.

35. Shigei, M.; Ahrens, L.; Hazaymeh, A.; Dalahmeh, S.S. Per- and polyfluoroalkyl substances in water and soil in wastewaterirrigated farmland in Jordan. Sci. Total Environ. 2020, 716, 137057. [CrossRef]

36. Dalahmeh, S.; Ahrens, L.; Gros, M.; Wiberg, K.; Pell, M. Potential of biochar filters for onsite sewage treatment: Adsorption and biological degradation of pharmaceuticals in laboratory filters with active, inactive and no biofilm. Sci. Total Environ. 2018, 612, 192-201. [CrossRef]

37. Dalahmeh, S.S.; Assayed, A.; Stenström, Y. Combined Vertical-Horizontal Flow Biochar Filter for Onsite Wastewater TreatmentRemoval of Organic Matter, Nitrogen and Pathogens. Appl. Sci. 2019, 9, 5386. [CrossRef]

38. Gros, M.; Ahrens, L.; Levén, L.; Koch, A.; Dalahmeh, S.; Ljung, E.; Lundin, G.; Jönsson, H.; Eveborn, D.; Wiberg, K. Pharmaceuticals in source separated sanitation systems: Fecal sludge and blackwater treatment. Sci. Total Environ. 2019, 703, 135530. [CrossRef]

39. Eaton, A.D.; Clesceri, L.S.; Greenberg, A.E.; Franson, M.A.H.; American Public Health Association; American Water Works Association; Water Environment Federation. Standard Methods for the Examination of Water and Wastewater; American Public Health Association: Washington, DC, USA, 1998; ISBN 978-0-87553-235-6.

40. Buerge, I.I.; Poiger, T.; Müller, M.D.; Buser, H.-R. Caffeine, an anthropogenic marker for wastewater comtamination of surface waters. Environ. Sci. Technol. 2003, 37, 691-700. [CrossRef]

41. Gros, M.; Rodríguez-Mozaz, S.; Barceló, D. Rapid analysis of multiclass antibiotic residues and some of their metabolites in hospital, urban wastewater and river water by ultra-high-performance liquid chromatography coupled to quadrupole-linear ion trap tandem mass spectrometry. J. Chromatogr. A 2013, 1292, 173-188. [CrossRef]

42. Lajeunesse, A.; Smyth, S.A.; Barclay, K.; Sauvé, S.; Gagnon, C. Distribution of antidepressant residues in wastewater and biosolids following different treatment processes by municipal wastewater treatment plants in Canada. Water Res. 2012, 46, 5600-5612. [CrossRef]

43. Baresel, C.; Cousins, A.P.; Hörsing, M.; Ek, M.; Ejhed, H.; Allard, A.-S.; Magnér, J.; Westling, K.; Wahlberg, C.; Fortkamp, U.; et al. Pharmaceutical Residues and Other Emerging Substances in the Effluent of Sewage Treatment Plants; Swedish Environmental Reserch Institute: Stockholm, Sweden, 2015; p. 118.

44. Couto, C.F.; Lange, L.C.; Amaral, M.C.S. Occurrence, fate and removal of pharmaceutically active compounds (PhACs) in water and wastewater treatment plants-A review. J. Water Process Eng. 2019, 32, 100927. [CrossRef] 
45. Kulkarni, P.; Olson, N.D.; Raspanti, G.A.; Rosenberg Goldstein, R.E.; Gibbs, S.G.; Sapkota, A.; Sapkota, A.R. Antibiotic Concentrations Decrease during Wastewater Treatment but Persist at Low Levels in Reclaimed Water. Int. J. Environ. Res. Public. Health 2017, 14, 668. [CrossRef] [PubMed]

46. Le-Minh, N.; Khan, S.J.; Drewes, J.E.; Stuetz, R.M. Fate of antibiotics during municipal water recycling treatment processes. Water Res. 2010, 44, 4295-4323. [CrossRef] [PubMed]

47. Al-Tarawneh, I.; El-Dosoky, M.; Alawi, M.; Batarseh, M.; Widyasari, A.; Kreuzig, R.; Bahadir, M. Studies on Human Pharmaceuticals in Jordanian Wastewater Samples. CLEAN-Soil Air Water 2015, 43, 504-511. [CrossRef]

48. Carmona, E.; Andreu, V.; Picó, Y. Occurrence of acidic pharmaceuticals and personal care products in Turia River Basin: From waste to drinking water. Sci. Total Environ. 2014, 484, 53-63. [CrossRef] [PubMed]

49. Yang, Y.-Y.; Toor, G.; Williams, C. Pharmaceuticals and organochlorine pesticides in sediments of an urban river in Florida, USA. J. Soils Sediments 2015, 15, 993-1004. [CrossRef]

50. Kadlec, R.H.; Wallace, S.D. Treatment Wetlands, 2nd ed.; CRC Press: Boca Raton, FL, USA, 2009; ISBN 978-1-56670-526-4.

51. Mandaric, L.; Kalogianni, E.; Skoulikidis, N.; Petrovic, M.; Sabater, S. Contamination patterns and attenuation of pharmaceuticals in a temporary Mediterranean river. Sci. Total Environ. 2019, 647, 561-569. [CrossRef] [PubMed] 